\title{
The effect of different stock densities on the performance of giant prawns (Macrobracium rosenbergii) and rice production in the minapadi system
}

\author{
Mahendra Mahendra ${ }^{1 *}$, Farah Diana ${ }^{1}$ and Giovanni Oktavinanda ${ }^{2}$ \\ ${ }^{1}$ Aquaculture Study Program, Faculty of Fisheries and Marine Science, Teuku Umar University, West Aceh, Indonesia. \\ ${ }^{2}$ Marine science Study Program, Faculty of Fisheries and Marine Science, Teuku Umar University, West Aceh, Indonesia.
}

\begin{abstract}
Minapadi is a prawn rearing system in rice fields that is carried out with rice plants. This study aims to increase the income of farmers with high productivity of rice yields and increase the production of giant prawns. The method used is a Completely Randomized Design (CRD) experiment with 3 treatments and 3 replications. The treatments were : P1 = stocking density of 100 ind/plot, $\mathrm{P} 2=$ stocking density of 200 ind/plot, P3 = stocking density of 300 ind/plot. This research was conducted for 90 days. Parameters observed were rice productivity and growth. The results showed that the best treatment was $\mathrm{P} 2=$ stocking density of $200 \mathrm{ind} / \mathrm{plot}$. By producing an average rice productivity of $5.5 \mathrm{~kg} / 50 \mathrm{~m}^{2}$ and the average relative growth rate of $4.72 \%$. From the results of this study, the application of the Minapadi system with giant prawns had a positive impact on the observed parameters $(\mathrm{P}<0.05)$ and thus will provide benefits for farmers.
\end{abstract}

\section{Introduction}

Fish farming businesses in Aceh Province have begun to develop, Howeversadly the types that are kept are foreign fish introduced from outside Aceh and evenoutside the Indonesia. This condition puts pressure on the local native fish population. Meanwhile, Aceh also has the potential for native fish that are not inferior both in terms of quantity and quality, for example giant prawns (Macrobrachium rosenbergii) [1].

The very fast population increase can cause more limited area production that can be used for various fields of fishery business, Therefore, it is necessary to utilize the existing land through intensification. One way that can be done is by implementing the Minapadi system.

Minapadi is a system of growing rice with fish cultivation in one rice field simultaneously. The potential for developing Minapadi cultivation is still very huge. Nationally the use of land for Minapadi cultivation only amounts to 127,944 hectares of the potential land area of 1,538,379 hectares. Thus, the level of land use for rice cultivation is only about $8.3 \%$. Therefore, the Ministry of Marine Affairs and Fisheries through the Directorate General of Aquaculture has promoted the Minapadi cultivation program to support the target of aquaculture production [2].

Giant prawns (Macrobracium rosenbergii) is one of the most potential aquatic species to be reared in the Minapadi system. The implementation of the Minapadi system with giant prawns has been implemented by a research team whose growth is very good in the Nagan Raya area [3]. However, the optimum stocking density of a high production minapadi system is still unknown. Therefore, we conducted this study to investigate the ideal stocking density of Macrobracium resonbergii that able to generate the highest productivity of paddy and the prawns.

\section{Research method}

\subsection{Research sites}

This research was conducted in the rice fields of Pante Ceureumen District, West Aceh Regency. The research location is at the coordinates of 4.430299, 96.299837.

\subsection{Experimental design}

The experimental method used in this study is a Completely Randomized Design (CRD) consisting of 3 treatments with 3 replications each. The treatment of each material used in this study includes:

$\mathrm{P} 1=$ Stocking density of $100 \mathrm{ind} / \mathrm{plot}$

$\mathrm{P} 2=$ Stocking density of $200 \mathrm{ind} / \mathrm{plot}$

P3 = Stocking density of 300 ind/plot

\subsection{Research procedure}

This research was conducted in rice fields with a total of 9 plots with an area of $5 \times 10$ meters per plot. Rice field bunds were constructed with height of $60 \mathrm{~cm}$, base width of $60 \mathrm{~cm}$ and upper width of $30 \mathrm{~cm}$, while the trenches (kemalir) according to the Legowo system treatment

*Corresponding author : mahendra@utu.ac.id 
were dug with the size of $30-60 \mathrm{~cm}$ wide and $40 \mathrm{~cm}$ deep. The rice variety used is resistant to waterlogging and pest attack, namely MAPAN which was planted after 30 days with spaces of $25 \times 12.5 \mathrm{~cm}$. The number of seedlings planted was 2 - 3 stems per clump. Shrimp (Macrobracium rosenbergii) stocking was done when the plants were 30 days old with a water level of $10 \mathrm{~cm}$. Stocking density treatment according to the experimental design was done in the afternoons to avoid stress to the Giant prawns. The shrimp (Macrobracium rosenbergii) were reared in the Minapadi system for 90 days with daily feedings of 3 times, namely in the morning, afternoon and evening. The maximum dose given was $3 \%$ of the total biomass with the frequency of administration three times a day. Shrimp (Macrobracium rosenbergii) harvest iswas done 90 days after the rice planting rice. Rice was observed for its productivity, while the shrimp (Macrobracium rosenbergii) was its growth and survival.

\subsection{Research Parameters}

\subsubsection{Rice productivity}

Productivity of the rice was calculated according to [4] using the formula:

$$
\text { Rice productivity }=\frac{\text { Production quantity }(\mathrm{Kg})}{\text { land } \text { area }(\mathrm{ha})}
$$

\subsubsection{Relative Growth Rate (RGR)}

The relative growth rate of giant prawns was calculated using the following formula by [3]:

$$
\begin{aligned}
& \mathrm{RGR}=\frac{\mathrm{Wt}-\mathrm{W} 0}{\mathrm{~W} 0 \times \mathrm{t}} \times 100 \% \\
& \text { Information: } \\
& \mathrm{SGR}=\text { Relative growth rate } \\
& \mathrm{Wt} \quad=\text { Prawn's Weight at the end of research } \\
& \mathrm{W} 0 \quad=\text { Prawn's Weight at the beginning research } \\
& \mathrm{t}=\text { Research time (90 day) }
\end{aligned}
$$

\subsubsection{Analysis Data}

The data obtained Data obtained were grouped, tabulated and statistically tested using ANOVA and SPSS to see the effect of the experiment. If there was a significant difference, a further Tukey test was be carried out.

\section{Results and Discussion}

\subsection{Rice productivity}

The results obtained from the research on rice productivity during maintenance can be seen in Figure 1. The highest rice productivity value in this study was P1 treatment with a value of $5.5 \mathrm{~kg} / \mathrm{plot}$. While the lowest in the P3 treatment was $4.6 \mathrm{~kg} / \mathrm{plot}$. According to [5] there was an increase in land productivity from 5,652 $\mathrm{kg} /$ ha to $7,612 \mathrm{~kg} / \mathrm{ha}$. Rice and Minapadi area are the same, but the proportion of Minapadi is $90 \%$ for rice cultivation and $10 \%$ for fish farming.

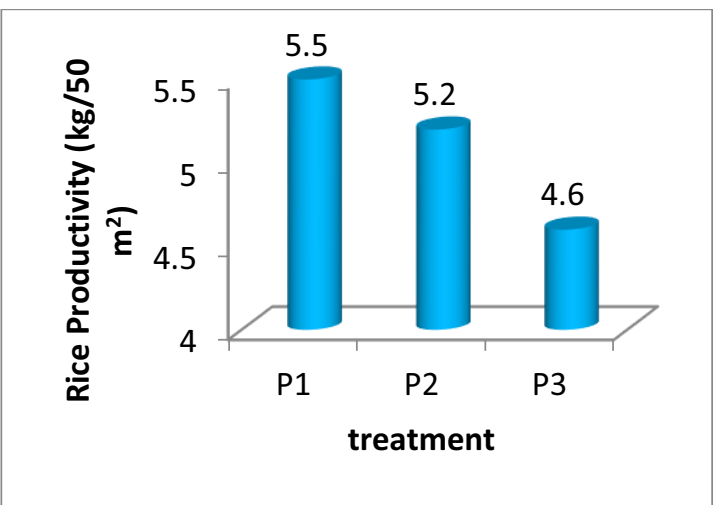

Fig. 1. Rice Productivity of Minapadi system by rearing Macrobracium rosenbergii

Minapadi cultivation is said to be successful when rice production is at least the same as production before implementation of Minapadi system. The ability of land in production is better when implementing Minapadi system. Efforts to increase productivity are achieved through improving soil conditions and intensive handling of pests and weeds [6].

The high productivity of rice in the $\mathrm{P} 1$ treatment is suspected to be due to the pellet feed when the pellets given were not consumed by the shrimp (Macrobracium rosenbergii) because there was an abundance of natural feed that was preferred by shrimp (Macrobracium rosenbergii). Thus the finished pellets will accumulate to become fertilizer which was readily absorbed by the rice plants. According to [7], nitrogen which is the main nutrient for plant growth, is absorbed by plant roots in the form of NO3- (nitrate) and NH4+ (ammonium).

\subsubsection{Relative Growth Rate}

The results of the relative growth rate of giant prawns in each treatment and replication for 90 days of rearing period are presented in Figure 2.

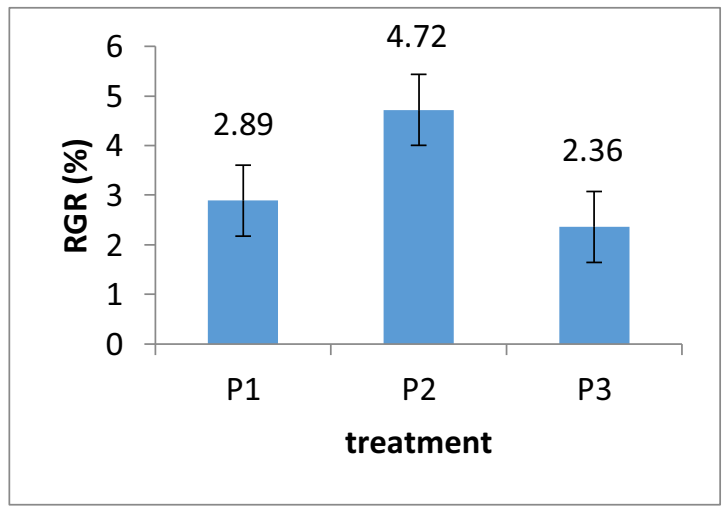

Fig. 2. Relative growth rate of giant prawns in the three treatments

Growth is a combination of behavioral processes and physiological processes. The physiological process is the process of using the consumed feed, while the behavior is the way of consuming the feed. The amount of food consumed by giant prawns is influenced by 
species, age, size, food availability, nutritional value, and environmental conditions [8].

Figure 2 show that the lowest relative growth rate value in this study was the P3 treatment with a value of $2.36 \%$. Meanwhile, the highest relative growth rate was found in P2 treatment with a value of $4.72 \%$. The results of this study indicate that different stocking densities in the Minapadi system play a role in supporting the growth of giant prawns.

The stocking density of $200 \mathrm{ind} /$ plot was the most effective with a size of $50 \mathrm{~m}^{2}$, compared to the stocking densities of 100 and $300 \mathrm{ind} /$ plot. The higher stocking density will affect the competition for feed consumption, oxygen and space for amongst the shrimp (Macrobracium rosenbergii). Therefore, the stocking density of moderate P2 was more effective. On the other hand, the stocking density of $100 \mathrm{ind} / \mathrm{plot}$ is the least with the growth being less effective. It is suspected that the feed in the form of pellets given is was not consumed by the shrimp (Macrobracium rosenbergii), because there was an abundance of natural feed which was preferred by the shrimp (Macrobracium rosenbergii). Thus the remaining pellets will accumulate into absorbed fertilizer by the rice plants. This can be seen in the productivity of the rice plants in $\mathrm{P} 1$ treatment which was higher than other treatments (Figure 1).

Some aspects of physiological processes related to individual growth of the giant prawns include regeneration, metamorphosis and moulting. Moulting is the process of periodically releasing old shells and the formation of new, larger shells. In crustaceans, growth occurs periodically after moulting. Body weight gain will be hampered if it is not preceded by the moulting process [9].

A high growth rate is characterized by a faster molting process. The process of transferring minerals from hemolymph to shrimp shells requires a lot of energy. This large energy requirement is obtained from the feed consumed. Feeding is an energy requirement to support a faster growth rate. This is closely related to growth where if feed consumption is high, there is a lot of energy available that can be used for various life needs and by reducing energy expenditure, so that the portion of energy available for growth is greater. If the physiology of shrimp goes well, including metabolism, then the utilization of feed is more efficient which ultimately increases growth [10].

\section{Conclusion}

Different stocking densities affect the growth of giant prawns. The best stocking density of $200 \mathrm{ind} /$ plot which resulted in the maximum growth of giant prawns at 4.72 $\%$ and the average rice productivity is $5.5 \mathrm{~kg} / \mathrm{plot}$.

Acknowledgments. The author's research was funded by internal research grants from Teuku Umar University, especially LPPM and Quality Assurance as well as the Aquaculture Study Program, Faculty of Fisheries and Marine Sciences.

\section{References}

1. E. Erlangga. J. BPT. 44, 1 (2016)

2. KKP Indonesia.. Minapadi System Fish Cultivation. Directorate General of Aquaculture. Jakarta, (2018)

3. M. Mahendra, F. Saputra, C.D. Febrina, D. Islama. J. KAM. 3,2 : 286 - 298, (2019)

4. E. Silamat, Yuwana, M.Z. Yuliarso. ISSN: 14128837, (2014)

5. D.R. Julistia. Analysis of Minapadi Farming Income in Margoluwih Village, Seyegan District, Sleman Regency. [Essay]. Bogor Agricultural University, (2017)

6. L.F.I. Tysno,. Analysis of Minapadi Farming Income. [Essay]. Bogor: Bogor Agricultural University, (2018)

7. E. Kaya. J. Agrologia, 2, 1 (2013)

8. T. Kadarini. Effect of Salinity and Calcium on Survival and Seed Growth of Balashark (Balanthiocheilus melanopterus). Thesis. Bogor Agricultural University, (2009)

9. R. Affandi, U.M. Tang. Physiology of Aquatic Animals. Riau University, Riau, (2002)

10. A.B. Zaidy. Utilization of Aquatic Calcium in the Molting Process and Its Consequences for the Growth of Giant Prawns (Macrobrachium rosenbergii de Man). Dissertation. Bogor Agricultural University, (2007) 